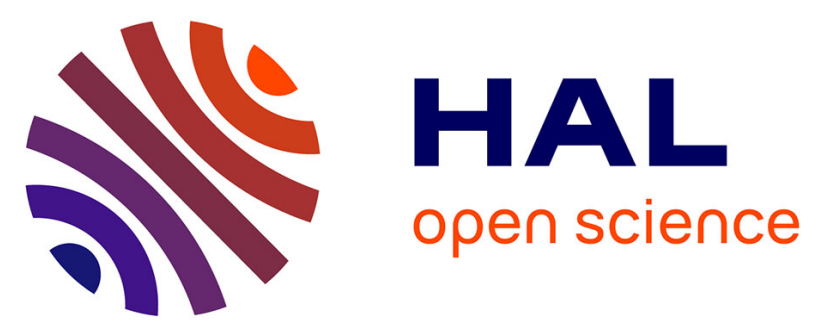

\title{
Correlation between heart rate and performance during Olympic windsurfing competition
}

Karim Chamari, Imen Moussa-Chamari, Olivier Galy, Mustapha Chaouachi, Donia Koubaa, Chokri Ben Hassen, Olivier Hue

\section{To cite this version:}

Karim Chamari, Imen Moussa-Chamari, Olivier Galy, Mustapha Chaouachi, Donia Koubaa, et al.. Correlation between heart rate and performance during Olympic windsurfing competition. European Journal of Applied Physiology, 2003, pp.387-392. hal-00720564

\section{HAL Id: hal-00720564 https://hal.univ-antilles.fr/hal-00720564}

Submitted on 24 Jul 2012

HAL is a multi-disciplinary open access archive for the deposit and dissemination of scientific research documents, whether they are published or not. The documents may come from teaching and research institutions in France or abroad, or from public or private research centers.
L'archive ouverte pluridisciplinaire HAL, est destinée au dépôt et à la diffusion de documents scientifiques de niveau recherche, publiés ou non, émanant des établissements d'enseignement et de recherche français ou étrangers, des laboratoires publics ou privés. 


\section{Karim Chamari · Imen Moussa-Chamari \\ Olivier Galy · Mustapha Chaouachi \\ Donia Koubaa · Chokri Ben Hassen · Olivier Hue \\ Correlation between heart rate and performance during Olympic windsurfing competition}

Accepted: 21 January 2003/Published online: 1 April 2003

(C) Springer-Verlag 2003

\begin{abstract}
The aim of this study was to examine the heart rate (HR) response to Olympic windsurfing competition and to check if there was any correlation between racing $\mathrm{HR}$, performance, and the variables measured during laboratory maximal exercise. Ten elite windsurfers [age: 20.93 (3.46) years; height: $178.10(6.34) \mathrm{cm}$; body mass: $66.79(5.90) \mathrm{kg}$ ] performed a laboratory maximal oxygen consumption $\left(V \mathrm{O}_{2 \max }\right)$ trial and national windsurf competitions wearing a HR monitor. One hundred and forty-three individual races were examined. Racing HR was expressed as a percentage of (1) $\mathrm{HR}_{\max }$ (maximal treadmill $\mathrm{HR})$ and (2) $\mathrm{HR}_{\text {reserve }}\left(\mathrm{HR}_{\max }-\mathrm{HR}_{\text {rest }}\right)$. The performance (racing classification: $\mathrm{RC}$, which is inversely proportional to performance) was significantly correlated to the racing HR response in both light wind $(\mathrm{LW}): \quad \mathrm{LW}-\mathrm{RC}=-0.12\left(\% \mathrm{HR}_{\text {reserve }}\right)+13.03$; $r=-0.71, r^{2}=0.50, p<0.001$, and medium wind (MW): $\mathrm{MW}-\mathrm{RC}=-0.11\left(\% \mathrm{HR}_{\text {reserve }}\right)+10.99 ; \quad r=-0.66$, $r^{2}=0.43, p<0.001$. The results showed similar correlations between performance and $\% \mathrm{HR}_{\max }$. Post racing lactate concentration was higher in LW compared to MW [7.14 (0.21) and $5.18(2.02) \mathrm{mmol} \cdot \mathrm{l}^{-1}$, respectively]. There was a negative correlation between the highest racing $\mathrm{HR}\left(\% \mathrm{HR}_{\text {reserve }}\right)$ of each athlete and the second ventilatory threshold expressed as a percentage of $V \mathrm{O}_{2 \max }(r=-0.71, p<0.05)$. To summarize, this study showed that light and medium wind Olympic windsurfing performances are highly dependent on the capacity of the athlete to maintain a high HR for long
\end{abstract}

O. Galy $\cdot$ O. Hue $(\bowtie)$

Laboratoire ACTES, Université des Antilles et de la Guyane, Campus de Fouillole, 97139 Pointe à Pitre, France

E-mail: HueO@wanadoo.fr

Tel.: + 33-590-901768

Fax: $+33-590-901768$

K. Chamari · D. Koubaa

National Centre of Sports Medicine, El Menzah, Tunisia

I. Moussa-Chamari · M. Chaouachi · C. B. Hassen Institut Supérieur du Sport et de l'Education Physique, Ksar, Saïd, Tunisia periods of time. Furthermore, windsurfing is highly dependent on the athlete's physical fitness level as shown by the correlations between racing HRs and laboratory physiological variables.

Keywords Aerobic power International-level sailboarders · Lactate

\section{Introduction}

A windsurfing competition was organized in the Olympic games for the first time in 1984. For the three first Olympics (Los Angeles 1984, Seoul 1988, and Barcelona 1992) the international racing rules did not allow for open or unlimited "pumping". Windsurfing was then usually classified as a "technical" sport. Since November 1992, "pumping" has been allowed in all Olympic windsurfing competitions (De Vito et al. 1997; Guével et al. 1999; ISAF; Vogiatzis et al. 2002). The action of pumping consists of moving the rig repeatedly in order to add an extra propulsion to the board, allowing the windsurfer to reach higher speeds and obtain a better result. Since then, the importance of physical training has taken up a larger part of the windsurfers' overall training program (De Vito et al. 1997; Guével et al. 1999; Vogiatzis et al. 2002). Indeed, pumping requires the windsurfer to perform successive flexion-extension movements of the upper and lower limbs during an entire race, which usually lasts $\sim 25-50 \mathrm{~min}$ (Guével et al. 2000). In this context, Guével et al. (1999) has shown that mean windsurfing racing $\mathrm{HR}$ in elite athletes was higher than $80 \%$ of maximum heart rate $\left(\mathrm{HR}_{\max }\right)$ with higher values for light wind with respect to moderate wind conditions [87.4 (4.3)\% vs. $82.9(5.3) \%$ of $\mathrm{HR}_{\max }$, respectively] for races that were usually longer than 30 min. De Vito et al. (1997) have observed even higher values reaching $92 \%$ of $\mathrm{HR}_{\max }$ and concluded that the windsurfers could be considered as endurance athletes. This was further confirmed by Vogiatzis et al. (2002). It 
has also been suggested that the ability of the windsurfer to maintain continuous pumping for the whole race duration is an important factor for performance under conditions of light or medium wind (Guével et al. 2000).

Several authors studying the relation between exercise intensity and the HR responses have shown that, in aerobic activities, $\mathrm{HR}$ is a linear function of exercise intensity (ACSM 1978; Léger 1994). Moreover, it has been shown that the HR value expressed as a percentage of $\mathrm{HR}_{\max }$ is more representative of exercise intensity than the absolute HR value (Gilman and Wells 1993; Londeree et al. 1995). Furthermore, when expressed as a percentage of $H_{R}$ reserve (i.e. $H R_{\text {max }}-H R_{\text {rest }}$ ), the $H R$ was closely related to oxygen consumption (Gilman 1996). Consequently, even if the cardiorespiratory variables are not actually measured, the HR measurement is representative of continuous exercise intensity. As mentioned above, windsurfing performance depends partially on the ability of the windsurfer to pump continuously, resulting in a high HR. Then, it can be hypothesized that windsurfing HR during competition is correlated to the actual performance of the athlete. The aim of this study was then to measure the HR during windsurfing regattas in light and moderate wind conditions in order to verify if this variable is correlated with the athlete's performance. Furthermore, as the ability to maintain a high HR for long periods of time is dependent on good physical fitness, the relation between sailing HRs and aerobic power variables was also checked.

\section{Methods}

\section{Subjects}

Ten windsurfers (nine males and one female) volunteered to participate in the study and provided written informed consent. The subjects were reminded that withdrawal from the study was possible at any time. For the physical characteristics of the subjects see Table 1.

All subjects were members of the Tunisian and Turkish Windsurfing National teams. They had regularly participated in six to eight international events per year for at least the previous 2 years (World and European Championships, and European Olympic sailing weeks). Their averaged weekly training programs included two running, two muscle strengthening, and four to six windsurfing sessions. The study was approved by the University ethics committee.

\section{Testing protocol}

Light wind (LW) and medium wind (MW) were defined as wind speeds ranging from 5 to 9 knots $\left(2.57-4.63 \mathrm{~m} \cdot \mathrm{s}^{-1}\right)$, and 10 to 16 knots $\left(5.14-8.23 \mathrm{~m} \cdot \mathrm{s}^{-1}\right)$, respectively. The races with too much wind variation switching from LW to MW were excluded from the analysis. Wind speed was measured with an anemometer (Plastimo,

Table 1 Subjects' characteristics $(n=10)$

\begin{tabular}{lccc}
\hline Value & Age (years) & Body mass $(\mathrm{kg})$ & Height $(\mathrm{cm})$ \\
\hline Mean & 20.93 & 66.79 & 178.10 \\
SD & 3.46 & 5.90 & 6.34 \\
\hline
\end{tabular}

France) at the beginning of the race and every $10 \mathrm{~min}$ throughout the race. These values were then averaged to obtain the mean race wind speed. Data from 22 races (10 in LW and 12 in MW) were analysed. The averaged wind speeds for the LW and MW races were $6.30(1.31)$ knots $\left[3.24(0.67) \mathrm{m} \cdot \mathrm{s}^{-1}\right]$ and $14.25(2.43)$ knots [7.33 (1.25) $\mathrm{m}^{-1} \mathrm{~s}^{-1}$, respectively. Ambient temperature ranged between 22 and $27^{\circ} \mathrm{C}$ during the experiment. These Olympic windsurfing courses (Guével et al. 1999; ISAF) occurred over 42 days during a national competition period (June and July). A typical Olympic course consists of a succession of legs, such as upwind (beating movement with the sail at $\sim 45^{\circ}$ to the wind direction), reaching (crosswind movement with the sail angle between $\sim 45^{\circ}$ and $90^{\circ}$ ) and running (downwind movement in the direction of the wind with the sail at $\sim 90^{\circ}$ to the wind). These last two legs are also called "downwind". Each race consisted of two laps. Standard Olympic boards were used (Mistral One Design, $7.5-\mathrm{m}^{2}$ sail) and the subjects were allowed to perform their own warm-up (Guével et al. 1999). No changes in the usual racing procedure were required for the purposes of the experiment. As not all studied subjects participated in all the races, the analysis was of data from 61 individual races in LW and 82 in MW. At the end of each race the athletes were awarded classification points according to the current international rules (ISAF), i.e. one point for first place, two points for second, and so on. Each subject wore their HR monitor on land before their warm-up period. For each individual, the exact time of the start of the HR recording was noted. Each race was accurately timed with its strategic events, i.e. fleet start and individual finish. Then for each subject, the racing HR was isolated from the preand post-race HRs. The mean racing durations were $26 \mathrm{~min} 45 \mathrm{~s}$ ( 5 min $25 \mathrm{~s}$ ) and $40 \min 45 \mathrm{~s}(9 \min 2 \mathrm{~s})$ in LW and MW, respectively. As international windsurfing rules allow only $10 \mathrm{~min}$ for the fleet to complete the race after the winner's finish, the maximum difference of race duration between the athletes studied was 6 min $40 \mathrm{~s}$ and 8 min $10 \mathrm{~s}$ in LW and MW respectively.

On-sea HR measurements

HR was monitored with a HR monitor (Polar Vantage, Polar Electro, Kempele, Finland). The monitor consists of an electrode belt worn around the chest, a transmitter, and a wrist-mounted receiver. The sampling rate was set at $0.2 \mathrm{~Hz}$.

Blood sampling and determination of blood lactate concentration

Blood samples were collected 3 min after the end of one LW and two MW races (for some subjects). A total of $4 \mathrm{LW}$ and $10 \mathrm{MW}$ samples were analysed. The $20-\mu$ l samples of capillary blood were withdrawn from an earlobe with Microzym micropipettes. They were stored in tubes containing $180 \mu \mathrm{l}$ of a haemolytic solution to ensure good preservation of the samples at room temperature. Blood lactate concentration was subsequently measured using an enzymatic method (Microzym L, Setric Génie Industriel, Toulouse, France).

\section{Laboratory measurements}

During the competitive period, each subject came to the laboratory to perform a maximal graded exercise test. The tests were performed in the afternoon from $2 \mathrm{pm}$ to $5 \mathrm{pm}$ at a laboratory temperature of $20^{\circ} \mathrm{C}$ to $22^{\circ} \mathrm{C}$. The subjects were asked to abstain from: (1) exercise the day prior to the test and (2) drinking caffeine beverages on the day of the test.

\section{Maximal $\mathrm{O}_{2}$ consumption measurement}

A maximal graded exercise test on a treadmill allowed us to measure the subjects' maximum oxygen consumption $\left(V \mathrm{O}_{2 \max }\right)$. Prior to the test subjects lay quietly on a bed for $15 \mathrm{~min}$ for the 
measurement of their resting $\mathrm{HR}\left(\mathrm{HR}_{\mathrm{rest}}\right)$. Then the test was performed on a 0 graded treadmill (Woodway, Ergo XELG 90, Weil, Germany). It began with a 3-min warm-up period at $9 \mathrm{~km} \cdot \mathrm{h}^{-1}$, immediately followed by $1 \mathrm{~km} \cdot \mathrm{h}^{-1}$ increment every minute till exhaustion. Oxygen consumption $\left(V \mathrm{O}_{2}\right)$ was considered maximal $\left(V \mathrm{O}_{2 \max }\right)$ if the following criteria were achieved: (1) a levelling off of $V \mathrm{O}_{2}$ despite a treadmill speed increase; (2) a respiratory gas exchange ratio higher than 1.1, and (3) attainment of age theoretical $\mathrm{HR}_{\max } \pm 5 \mathrm{bpm}$. All the subjects achieved physiological criteria for $V \mathrm{O}_{2 \max }$. The peak $\mathrm{HR}$ attained at exhaustion during maximal graded exercise was considered to be $\mathrm{HR}_{\max }$ (Chamari et al. 1995). Exhaustion occurred within 10-15 min of exercise for all subjects. The measurement of the cardiorespiratory variables was performed with a breath-by-breath cardiorespiratory device (ZAN 680, Oberthulba, Germany). This system allowed the continuous measurement of HR, pulmonary gas exchange, and ventilation during the test. Prior to each test the gas analysers were calibrated with gases of known concentrations. The ventilatory membrane was calibrated with a 1-1 syringe. HR was determined from a six-lead ECG with 12 derivations. On the test reports, HR and the respiratory data were provided once every $30 \mathrm{~s}$ with the values averaged on the ten last respiratory cycles on a sliding technique basis (Whipp et al. 1982).

Establishment of the ventilatory thresholds

The two ventilatory thresholds, $\mathrm{Th} 1_{\text {vent }}$ and $\mathrm{Th} 2_{\text {vent }}$, i.e. anaerobic threshold and the respiratory compensation threshold, respectively, were established according to Beaver et al. (1986).

Expression of results

The windsurfing $\mathrm{HR}$ values are expressed as a percentage of: (1) $\mathrm{HR}_{\max }\left(\% \mathrm{HR}_{\max }\right)$ and (2) $\mathrm{HR}_{\text {reserve, }}$ i.e. $\mathrm{HR}_{\max }-\mathrm{HR}_{\text {rest }}$ $\left(\% \mathrm{HR}_{\text {reserve }}\right)$. For each subject, the race that resulted in the highest HR $\left(\% \mathrm{HR}_{\text {reserve }}\right)$ was called RacingPeak $\% \mathrm{HR}_{\text {reserve }}$.

For the maximal graded exercise, the following values were selected: $v_{\text {Peak }}$ (treadmill peak velocity attained at exhaustion in the $V \mathrm{O}_{2 \max }$ trial), the first and second ventilatory thresholds expressed as a percentage of $V \mathrm{O}_{2 \max }\left(\mathrm{Th} 1_{\text {vent }} \% V_{2 \max }\right.$ and $\mathrm{Th} 2_{\text {vent }} \% V \mathrm{O}_{2 \max }$, respectively). As Paavolaïnen et al. (1999) have shown that peak treadmill velocity is more correlated to endur-

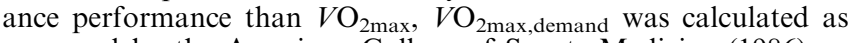
proposed by the American College of Sports Medicine (1986):

$V \mathrm{O}_{2 \text { max,demand }}\left(\mathrm{ml} \cdot \mathrm{kg}^{-1} \cdot \mathrm{min}^{-1}\right)=12 \cdot v\left(\mathrm{~m} \cdot \mathrm{s}^{-1}\right)+3.5($ with 0 graded treadmill), where $v$ is peak treadmill velocity.

\section{Statistics}

Values are expressed as mean (standard deviation). A Pearson correlation coefficient and linear regression analysis were performed between the mean HRs measured during the races and: (1) performance (number of points obtained), the athlete's body mass, and race duration, and (2) the physiological variables measured at

Table 2 Maximal treadmill graded exercise results. [ $\mathrm{VO}_{2 \max \text {,demand }}$ See Methods (Paavolaïnen et al. 1999), $v_{\text {Peak }}$ peak treadmill velocity at exhaustion, $H R_{\max }$ peak HR at exhaustion of maximal graded exercise, $T h 1_{\text {vent }} \% V O_{2 \max }$ first ventilatory threshold, or anaerobic

\begin{tabular}{|c|c|c|c|c|c|c|}
\hline Value & $\begin{array}{l}V \mathrm{O}_{2 \mathrm{max}} \\
\left(\mathrm{ml} \cdot \mathrm{kg}^{-1} \cdot \mathrm{min}^{-1}\right)\end{array}$ & $\begin{array}{l}V \mathrm{O}_{2 \mathrm{max} \text { demand }} \\
\left(\mathrm{ml} \cdot \mathrm{kg}^{-1} \cdot \mathrm{min}^{-1}\right)\end{array}$ & $\begin{array}{l}v_{\text {Peak }} \\
\left(\mathrm{km} \cdot \mathrm{h}^{-1}\right)\end{array}$ & $\begin{array}{l}\mathrm{HR}_{\max } \\
\text { (bpm) }\end{array}$ & $\begin{array}{l}\mathrm{Th} 1_{\text {vent }} \% \\
V \mathrm{O}_{2 \max }\end{array}$ & $\begin{array}{l}\mathrm{Th} 2_{\text {vent }} \% \\
V \mathrm{O}_{2 \max }\end{array}$ \\
\hline Mean & 62.48 & 65.87 & 18.71 & 194.10 & 74.09 & 88.30 \\
\hline SD & 9.23 & 6.84 & 2.05 & 9.57 & 5.05 & 5.66 \\
\hline
\end{tabular}

the laboratory. A linear regression analysis was realized between the racing HR and performance. With respect to the relationship between racing HR and the physiological variables, a forward stepwise multiple regression analysis was realized in order to establish which of the measured variables better explained the racing HR. The independent variables used in this analysis were the parameters of the $V \mathrm{O}_{2 \max }$ test, i.e. $V \mathrm{O}_{2 \max }, v_{\text {Peak }}, \mathrm{Th} 1_{\text {vent }} \% V \mathrm{O}_{2 \max }$, and $\mathrm{Th} 2_{\text {vent }} \% V \mathrm{O}_{2 \max }$. Statistical significance was fixed at the $p<0.05$ level.

\section{Results}

\section{Laboratory testing}

For the results of the maximal graded treadmill exercise see Table 2.

\section{Sailing HR measurements}

The mean HR for all the subjects in the LW and MW races represented 80.51 (6.82) and $76.20(8.47) \% \mathrm{HRmax}$, respectively. The linear regression analysis showed that there was a significant correlation between performance and racing $\mathrm{HR}$ in both $\mathrm{LW}$ and $\mathrm{MW}$.

In $\mathrm{LW}$, the relationship between racing classification and the $\mathrm{HR}$ values expressed as $\% \mathrm{HR}_{\text {reserve }}$ were related by the formula: Racing Classification Points $(\mathrm{LW})=-0.12\left(\% \mathrm{HR}_{\text {reserve }}\right)+13.03 ; r=-0.71, r^{2}=0.50$, $p<0.001$ (Fig. 1). Racing HR expressed as $\% \mathrm{HR}_{\max }$ was also significantly correlated to the racing classification points $(r=-0.70, p<0.001)$.

In MW, the relationship between racing classification and the $\mathrm{HR}$ values expressed as $\% \mathrm{HR}_{\text {reserve }}$ were related by the formula: Racing Classification Points $(\mathrm{MW})=-0.11\left(\% \mathrm{HR}_{\text {reserve }}\right)+10.99 ; r=-0.66, r^{2}=0.43$, $p<0.001$ (Fig. 2). Racing $\mathrm{HR}$ expressed as \% $\mathrm{HR}_{\max }$ was also significantly correlated to the racing classification points $(r=-0.66, p<0.001)$.

These correlations were not influenced by the race duration as there was no correlation between $\% \mathrm{HR}_{\text {reserve }}$ and race duration, $r=0.03, p=0.70(n=143)$.

For wind speeds over 12.5 knots $\left(6.43 \mathrm{~m} \cdot \mathrm{s}^{-1}\right)$, the correlation was significant between body mass and racing points classification $\left(r=-0.451, r^{2}=0.203, p<0.001\right.$, $n=54)$. There was no correlation between body mass and performance in LW or MW between 10 and 12.5 knots: $r=0.085, p=0.515(n=61)$ and $r=0.006$, $p=0.975(n=28)$, respectively.

threshold expressed as a percentage of $V \mathrm{O}_{2 \max }, T h 2_{\text {vent }} \% V O_{2 \max }$ second ventilatory threshold or respiratory compensation threshold expressed as a percentage of $\left.V \mathrm{O}_{2 \max }\right]$ 


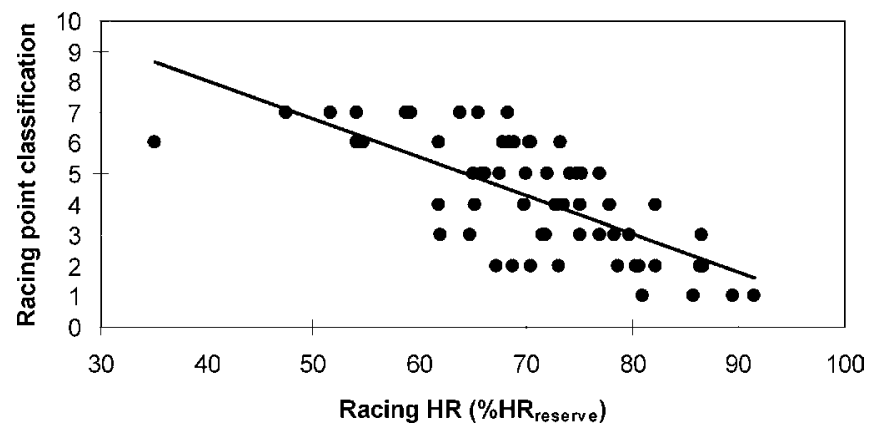

Fig. 1 Linear regression between racing heart rate $\left(\% \mathrm{HR}_{\text {reserve }}\right)$ and racing classification points in light wind (5-9 knots, $n=61)$

Post-racing lactate concentrations were higher in LW compared to MW: $7.14(0.21)$ and $5.18(2.02) \mathrm{mmol} \cdot \mathrm{l}^{-1}$, respectively $(t=3.01, p<0.01)$.

\section{Relation between sailing HR and laboratory testing}

The Pearson correlation matrix showed that there were some significant relationships between sailing HR measurements and laboratory variables. When the highest individual racing $\mathrm{HR}\left(\% \mathrm{HR}_{\text {reserve }}\right)$ was plotted against the main aerobic power variables, the stepwise regression analysis showed that $51 \%$ of the racing HR was explained by the second ventilatory threshold:

$$
\begin{aligned}
\text { RacingPeak } \% \mathrm{HR}_{\text {reserve }}= & -0.88 \cdot\left(\mathrm{Th} 2_{\text {vent }} \% \dot{V} O_{2 \max }\right) \\
& +157.83
\end{aligned}
$$

$r=-0.71, r^{2}=0.51, p<0.05$.

\section{Discussion}

The present study showed that there was a positive correlation between the Olympic windsurfing performance and racing HR in both LW and MW conditions. Furthermore the relationship between windsurfing racing HR and laboratory variables showed that the higher individual $\mathrm{HR}$ (expressed as a percentage of $\mathrm{HR}_{\text {reserve}}$ ) was negatively correlated to the second ventilatory threshold expressed as a percentage of $V \mathrm{O}_{2 \max }$.

Despite the possible effect of some non-physiological variables on $\mathrm{HR}$ and the fact that $\mathrm{HR}$ measurement is an indirect estimation of the cardiorespiratory responses, it is widely admitted that this variable is a good indicator of continuous exercise intensity (ACSM 1978; Léger 1994). It has been shown that the HR expressed as a percentage of $\mathrm{HR}_{\max }$ is more representative of exercise intensity than the absolute HR value (Gilman and Wells 1993; Londeree et al. 1995). Furthermore, when expressed as a percentage of $H_{\text {reserve, }}$, i.e. $H_{\mathrm{max}}-\mathrm{HR}_{\text {rest }}$, the $\mathrm{HR}$ was closely related to $V \mathrm{O}_{2}$ in continuous exercise (Gilman 1996). It has recently been shown that even if the exercise pattern is intermittent, in long aerobic exercise such as tennis, HR time course is similar to that of $V \mathrm{O}_{2}$ (Dansou et al. 2001). The present results show that the subjects sailed with HRs representing 80.5 and $76.2 \% \mathrm{HR}_{\max }$ in $\mathrm{LW}$ and $\mathrm{MW}$, respectively. This is slightly lower than values reported by Guével et al. (1999), namely 87.4 and $82.9 \%$ HRmax, respectively. This may not be due to race duration, as HR was not correlated to race duration in either study. De Vito et al. (1997) have reported even higher values representing about $92 \% \mathrm{HR}_{\max }$, but these values were measured over short periods of time in a race simulation. The slightly lower $\% \mathrm{HR}_{\max }$ values observed in the present study may not be explained by the presence of a female windsurfer in the group, as De Vito et al. (1997) and Vogiatzis et al. (2002) have shown similar $\% \mathrm{HR}_{\max }$ in male and female athletes when pumping. A possible cause of the lower relative HRs could be due to the pumping pattern of the studied subjects. Guével et al. (2000) have shown that two periods of 6-minutes simulated pumping with two frequencies $(1.5$ vs. $1 \mathrm{~Hz})$ with the same energy expenditure, resulted in a cardiac response representing 77.1 and $80.2 \% \mathrm{HRmax}$ respectively. The time to exhaustion (in a separate test) was threefold longer for the short and frequent pumping with respect to the high amplitude one. It is then possible that the present study subjects used more the short pumping than the subjects of Guével et al. (1999). It has been reported that if high magnitude pumping is more strenuous, it is more effective at increasing board speed (Guével et al. 2000). Lastly, an experimental difference could have caused the observed discrepancies in racing intensity, as Guével et al. (1999) only analysed the first race of each competition day. The present study analysed all the races sailed for a given day, which corresponded to two to three races a day with 15-20 min of recovery in between.
Fig. 2 Linear regression between racing heart rate $\left(\% \mathrm{HR}_{\text {reserve }}\right)$ and racing classification points in medium wind $(10-16$ knots, $n=82)$

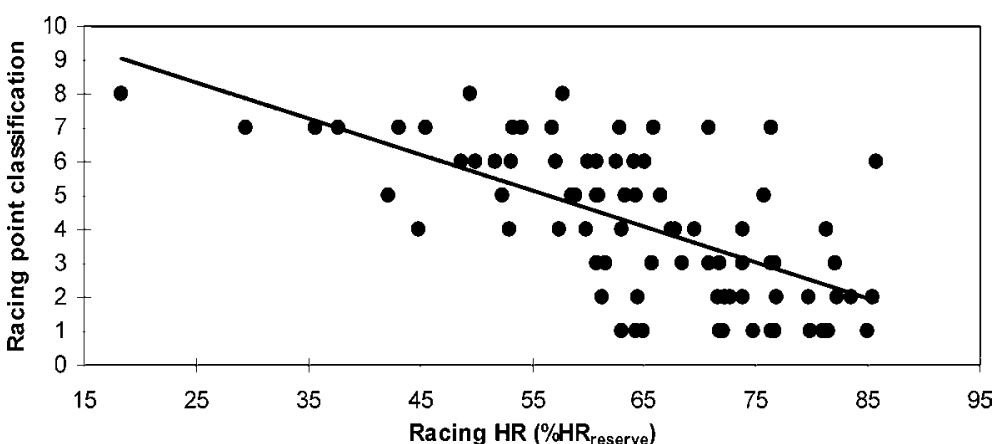


The cumulative effect of fatigue could have lowered sailing intensity for the second and third races of the day with respect to the first.

Despite its complex metabolism, lactate is thought to be a relevant indicator of anaerobic glycolysis during exercise (Brooks 1991). The post-racing lactate measured in the present study was similar to values reported by Chardigny et al. (1990), Guével et al. (1999) and De Vito et al. (1997) and confirms that Olympic windsurfing racing involves anaerobic metabolism. De Vito et al. (1997) have suggested that anaerobic conditions are related mostly to pumping. The present study's values may have been slightly underestimated, as the samples were taken from an earlobe whereas Guével et al. (1999) and De Vito et al. (1997) took blood from the fingertip. Indeed, Dassonville et al. (1998) have shown that fingertip post-exercise lactate values are significantly higher than earlobe values if the arms are involved in the exercise. Lastly, Guével et al. (1999) have clearly shown that the HR is significantly higher in the first half of the race than the second, probably for strategic purposes. Indeed, it seems that the athletes fight hard in the first half of the race to take a position as close as possible to the lead, and then the second part of the race serves to consolidate the windsurfer's position by a somewhat defensive attitude (Guével et al. 1999). This could have led to a further underestimate of the involvement of anaerobic metabolism. Indeed, no study has stopped a race at the end of the first half to measure blood lactate.

The exercise HR increases could be due to: (1) the exercise intensity per se and/or (2) to the type of muscle contractions. Indeed, De Vito et al. (1997) have noted that windsurfing is a mix of dynamic (e.g. arms, thighs) and static (e.g. trunk and forearms) contractions. Furthermore, the effect of the raised upper arms on the HR increase has to be considered (De Vito et al. 1997). As the races lasted for more than $20 \mathrm{~min}$ it is possible that cardiac drift also influenced the averaged HR values (Gilman 1996).

With respect to the relationship between sailing HRs and laboratory variables, there was a negative correlation between individual maximal sailing HR expressed as a percentage of $\mathrm{HR}_{\text {reserve }}$ and the second ventilatory threshold expressed as a percentage of $V \mathrm{O}_{2 \max }$. Billat and Koralsztein (1996) have reported that the second ventilatory threshold is a good indicator of aerobic power. One explanation for the observed negative correlation could be that subjects with lower thresholds have to make a greater relative effort than the fitter ones to generate similar work, resulting in a higher HR. In that case, it is possible that the fittest athletes were often sailing under or just at the level of their respective anaerobic threshold leading to a relatively moderate HR (De Vito et al. 1997). It is possible that the athletes with good aerobic power need only to make a relatively low effort during races against athletes with poorer fitness levels. The present results confirm that Olympic windsurfing is an endurance activity in which physiological variables have an important bearing on performance (De Vito et al. 1997). Indeed it has been reported that, depending on the part of the race, Olympic windsurfing can be compared to a 2000-m rowing event (i.e. 90-95\% $\mathrm{HR}_{\max }$ for about $6.5 \mathrm{~min}$ ) for the downwind leg and to what has been defined as the "efficient active recovery stage" of cycling and swimming $\left(75-80 \% \mathrm{HR}_{\max }\right)$ for the upwind leg (Guével et al. 2000).

To summarize, the present study showed that Olympic windsurfing performance depends upon the level of active involvement of each athlete during a race, indeed light and medium racing performances were correlated to the sailing HR, i.e. exercise intensity. These results reinforce the findings of former studies showing that from the moment "pumping" was allowed in international windsurfing events, racing intensity has increased. From 5 to 16 knots, a windsurfer's performance is greatly dependent on their ability to maintain continuous pumping, resulting in high heart rates. Windsurfing athletes and coaches should consider these findings when planning their physical training programs.

Acknowledgements The authors would like to thank Dr. JeanClaude Chatard for his valuable help and Tony Philp, Gaby Mkaouar, and Hajer Amri for their technical support.

\section{References}

American College of Sports Medicine (ACSM) (1978) The recommended quantity and quality of exercise for developing and maintaining fitness in healthy adults (position statement). Med Sci Sports 10:II-X

American College of Sports Medicine (ACSM) (1986) Guidelines for exercise testing and prescription, 3rd edn. Lea and Febiger, Philadelphia, p 168

Beaver WL, Wasserman K, Whipp BJ (1986) A new method for detecting anaerobic threshold by gas exchange. J Appl Physiol 60:2020-2027

Billat VL, Koralsztein JP (1996) Significance of the velocity at $V \mathrm{O}_{2 \max }$ and time to exhaustion at this velocity. Sports Med 22:90-108

Brooks GA (1991) Current concepts in lactate exchange. Med Sci Sports Exerc 23:895-906

Chamari K, Ahmaidi S, Fabre C, Ramonatxo M, Prefaut C (1995) Pulmonary gas exchange and ventilatory responses to brief intense intermittent exercise in young trained and untrained adults. Eur J Appl Physiol . 70:442-450

Chardigny JM, Moreau D, Chedeville J, Meurgey B (1990) Epreuve d'effort en planche à voile et lactatémie. In Eléments de Recherche en Voile. Mémento Technique. Publication Fédération Française de Voile. pp 65-73

Dansou P, Oddou MF, Delaire M, Therminarias A (2001) Dépense énergétique aérobie au cours d'un match de tennis, du laboratoire au terrain. Sci Sports 16:16-22

Dassonville J, Beillot J, Lessard Y, Jan J, André AM, Le Pourcelet C, Rochongar P, Carré F (1998) Blood lactate concentrations during exercise: effect of sampling site and exercise mode. J Sports Med Phys Fitness 38:39-46

De Vito G, Di Filippo L, Rodio A, Felici F, Madaffari A (1997) Is the Olympic boardsailor an endurance athlete? Int J Sports Med 18:281-284

Gilman MB (1996) The use of heart rate to monitor the intensity of endurance training. Sports Med 21:73-79 
Gilman MB, Wells CL (1993) The use of heart rates to monitor exercise intensity in relation to metabolic variables. Int J Sports Med 14:339-344

Guével A, Maïsetti O, Prou E, Dubois JJ, Marini JF (1999) Heart rate and blood lactate responses during competitive Olympic boardsailing. J Sports Sci 17:135-141

Guével A, Hogrel JY, Marini JF (2000) Fatigue elbow flexors during repeated flexion-extension cycles: effects of movement strategy. Int J Sports Med 21:492-498

International Sailing Association of Federations (ISAF). International Racing Rules 1992-1996 and 1996-2000

Léger L (1994) Significations et limites de l'utilisation de la fréquence cardiaque dans le contrôle de l'entraînement In: Cazorla $\mathrm{G}$, Robert $\mathrm{G}$ (eds) Actes du troisième colloque international de la Guadeloupe. Actshng et Areaps
Londeree BR, Thomas TR, Ziogas G, Smith TD, Zhang Q (1995) $\% V \mathrm{O}_{2 \max }$ versus $\% \mathrm{HR}_{\max }$ regressions for six modes of exercise. Med Sci Sports Exerc 27:458-461

Paavolaïnen L, Häkkinen K, Hämäläinen I, Nummela A, Rusko H (1999) Explosive-stregth training improves $5-\mathrm{km}$ running time by improving running economy and muscle power. J Appl Physiol 86:527-1533

Vogiatzis I, De Vito G, Rodio A, Madaffari A, Marchetti A (2002) The physiological demands of sail pumping in Olympic level windsurfers. Eur J Appl Physiol 86:450-454

Whipp BJ, Ward SA, Lamarra N, Davis JA, Wasserman K (1982) Parameters of ventilatory and gas exchange dynamics during exercise. J Appl Physiol 52:1506-1513 